\title{
ТЕХНОЛОГИЯ БЕТОНА, МОДИФИЦИРОВАННОГО КОМПЛЕКСНОЙ ДОБАВКОЙ ГИДРОТЕРМАЛЬНОГО НАНОКРЕМНЕЗЕМА И МНОГОСЛОЙНЫХ УГЛЕРОДНЫХ НАНОТРУБОК
}

\author{
Е. Н. Полонина ${ }^{1}$
}

${ }^{1}$ Магистр технических наук, старший преподаватель кафедры строительных материалов и технологии строительства учреждения образования «Белорусский национальный технический университет», Мuнск, Беларусь, e-mail: grushevskay_en@tut.by

\begin{abstract}
Реферат
В работе предложено применение взаимоусиливающей комбинации наночастиц с переходом в область малых доз (в 1000-10000 раз ниже традиционных), позволяющей применить относительной низкий расход поликарбоксилатного суперпластификатора одновременно для снижения водопотребности бетонной смеси и стабилизации наночастиц; многослойных углеродных нанотрубок (МУНТ) отечественного производства с удельной поверхностью 60 м²/г, варьируемым отношением длина/диаметр I/d (в пределах 0,01-20 мкм/10-300 нм), высокой плотностью карбоксильных групп активированной поверхности и гидротермальных наночастиц кремнезема (золя нанокремнезема $\mathrm{SiO}_{2}$ ) со средним диаметром наночастиц 5,5 нм, удельной поверхностью 500 м²/г, плотностью поверхностных силанольных групп до 4,9 нм² в форме стабильного золя с высоким по модулю электрокинетическим потенциалом, исключающим необходимость диспергирования и стабилизации при приготовлении комплексной водной суспензии.
\end{abstract}

Ключевые слова: комплексная добавка, наночастицы, прочность, механизм, методы.

\section{ADVANCED CONCRETE TECHNOLOGIE MODIFIED BY COMPLEX ADDITION BASED ON SILICA-FUME AND NANO-TUBES}

\section{Abstract}

\section{E. N. Polonina}

The paper proposes the use of a mutually reinforcing combination of nanoparticles with a transition to the region of low doses (1000-10000 times lower than traditional ones), which makes it possible to apply a relatively low consumption of polycarboxylate superplasticizer simultaneously to reduce the water demand of the concrete mixture and stabilize the nanoparticles; multilayer carbon nanotubes (MCNTs) of domestic production with a specific surface area of $60 \mathrm{~m}^{2} / \mathrm{g}$, a variable length / diameter ratio I / $\mathrm{d}$ (in the range of 0.01-20 $\mu \mathrm{m} / 10-300 \mathrm{~nm}$ ), a high density of carboxyl groups of the activated surface and hydrothermal silica nanoparticles $\mathrm{SiO}_{2}$ with an average nanoparticle diameter of $5.5 \mathrm{~nm}$, specific surface area of $500 \mathrm{~m}^{2} / \mathrm{g}$, density of surface silanol groups up to $4.9 \mathrm{~nm}^{-2}$ in the form of a stable sol with a high modulus of electrokinetic potential, eliminating the need for dispersion and stabilization when preparing a complex aqueous suspension.

Keywords: complex additive, nanoparticles, strength, mechanism, methods.

\section{Введение}

Существенной современной чертой развития последних 20 лет 2000-2020 гг. в области портландцементных материалов стало направление, основанное на новых данных о структуре геля гидросиликатов кальция (CSH-геля), заполняющего до 70 \% и более объема бетона. Новые данные были во многом получены благодаря применению комбинации методов, в первую очередь, рентгенофазового анализа, сканирующей и туннельной электронной микроскопии, атомной силовой микроскопии, ИК-спектроскопии (инфракрасной спектроскопии), ЯМР (ядерного магнитного резонанса), наноиндентирования и численного моделирования энергетического состояния структуры, составленной из кремнекислородных тетраэдров $\mathrm{SiO}_{4}$ атомов $\mathrm{Ca}$ и $\mathrm{H}_{2} \mathrm{O}$. Появились возможности управляемого и контролируемого воздействия на структуру CSH-геля и эксплуатационные характеристики бетонов. Ввод наночастиц разного химического состава с высокой удельной площадью поверхности (до 1000 м²/г) и высокой физико-химической активностью поверхности в водоцементную систему стал перспективным приемом повышения характеристик цементных материалов [1-5].

Среди наночастиц разного химического состава $\mathrm{TiO}_{2}, \mathrm{Fe}_{2} \mathrm{O}_{3}$, $\mathrm{CuO}, \mathrm{CaCO}_{3}$ и др. с учетом эффрективности, себестоимости синтеза, возможности стабилизированного однородного ввода в бетонную смесь и наличия действующих крупных производств наночастицы $\mathrm{SiO}_{2}$ и наноуглерода стали наиболее применяемыми. Результатам повышения механических, физических и структурных характеристик портландцементного бетона и цементного камня посвящено большинство публикаций по строительным материалам [6-19].

Актуальность данной работы связана с необходимостью реальных проблем технологий наномодифицирования бетонов:

- совершенствования методов направленного и контролируемого регулирования структуры CSH-геля варьированием доз, размеров, физико-химических характеристик поверхности наночастиц и других способов;
- снижения себестоимости технологии наномодифицирования бетонов относительно эффректа повышения эксплуатационных характеристик;

- решения проблем стабилизированного и однородного ввода нанодобавок в бетонную с одновременным контролем за коэффициентом вариации бетона в крупногабаритных изделиях.

Свойства цементного камня, бетонных смесей и тяжелого наномодифицированного конструкционного бетона под влиянием УНМ, золя нанокремнезема и комплексной добавки

На основе технологий получения образцов концентрированного гидротермального золя $\mathrm{SiO}_{2}$ и углеродных нанотрубок реализована технология получения стабилизированной суспензии комплексной нанодобавкой. Разработанные рецептуры цементных материалов в диапазоне малых доз наночастиц представлены в таблице 1.

Результаты испытания цементного камня на прочность при сжатии и при изгибе при В/Ц =0, 21 и дозах НЧ 0,00004-0,000006 масс. \% приведены рис. 1, 2.

Исследования прочности при сжатии и изгибе цементного камня показали, что в раннем возрасте 1 сут и 3 сут разница между контрольным образцом цементного камня и образцами, модифицированными $\mathrm{HЧ} \mathrm{SiO}_{2}$ и $\mathrm{HЧ} \mathrm{SiO}_{2}+$ МУНТ (составов № 29-33) достигала 13 и $12,7 \%$, в возрасте 37 сут - 11,9\%, и была максимальной в случае применения комбинации $\mathrm{HЧ} \mathrm{SiO}_{2}$ + МУНТ (рис. 1). Разница по прочности при изгибе между контрольным образцом цементного камня и образцами, модифицированными указанными добавками была максимальной для образца с комплексной добавкой $\mathrm{HU} \mathrm{SiO}_{2}+\mathrm{MУHT}$ и в возрасте 1 сут и 3 сут достигала 39,6 и 21,6 \%, а в возрасте 37 сут $23,4 \%$ (рис. 2). Отношение $f_{t} / f_{c}$ возросло на $118,23 / 38,72=0,131$, что указывает на повышение упругопластических свойств и трещиностойкости цементного камня. 
Вестник Брестского государственного технического университета. 2021

Таблица 1 - Составы цементных материалов для исследований

\begin{tabular}{|c|c|c|c|c|c|c|c|c|c|c|c|c|c|c|}
\hline \multirow{3}{*}{ № } & \multirow{3}{*}{$\begin{array}{c}\text { Наименование } \\
\text { состава }\end{array}$} & \multicolumn{4}{|c|}{ Состав сырьевой смеси, кг/м³ } & \multicolumn{3}{|c|}{$\begin{array}{c}\text { Состав компонентов } \\
\text { по твердому веществу, } \\
\text { г/т добавки }\end{array}$} & \multirow{3}{*}{$\begin{array}{c}\text { OK } \\
\text { (PK) }\end{array}$} & \multirow{3}{*}{ В/Ц } & \multirow{3}{*}{$\begin{array}{c}\text { Количество } \\
\text { вводимой } \\
\text { добавки от } \\
\text { массы } \\
\text { цемента, \% }\end{array}$} & \multirow{3}{*}{$\begin{array}{c}\text { Массо- } \\
\text { вая доля } \\
\text { СП к } \\
\text { цемен- } \\
\text { ту,\% }\end{array}$} & \multirow{3}{*}{$\begin{array}{c}\text { Массовая } \\
\text { доля тв. } \\
\text { углерода к } \\
\text { цементу, \% }\end{array}$} & \multirow{3}{*}{$\begin{array}{l}\text { Массовая } \\
\text { доля тв. } \\
\mathrm{SiO}_{2} \\
\text { к цементу,\% }\end{array}$} \\
\hline & & \multirow{2}{*}{$\begin{array}{c}\text { Це- } \\
\text { мент }\end{array}$} & \multirow[b]{2}{*}{ Песок } & \multicolumn{2}{|c|}{ Щебень } & \multirow{2}{*}{$\begin{array}{l}\text { Концен- } \\
\text { трация } \\
\text { SP, \% }\end{array}$} & \multirow{2}{*}{$\begin{array}{c}\text { Золь } \\
\text { нано- } \\
\text { кремне- } \\
\text { зема }\end{array}$} & \multirow[b]{2}{*}{ Углерод } & & & & & & \\
\hline & & & & фp. 5-10 & фpp.10-20 & & & & & & & & & \\
\hline 1 & C1-RS & \multirow{18}{*}{350} & \multirow{18}{*}{975} & \multirow{18}{*}{-} & \multirow{18}{*}{1040} & - & - & - & 4 & 0,4 & - & - & - & - \\
\hline 2 & C1-SP & & & & & - & - & - & 2 & 0,26 & 0,8 & 0,4 & - & - \\
\hline 3 & $\mathrm{C} 1-\mathrm{NS}_{4700}$ & & & & & - & 4700 & & 3 & 0,5 & 0,8 & - & - & 0,003525 \\
\hline 4 & $\mathrm{C} 1-\mathrm{NS}_{470}$ & & & & & - & 470 & - & 2 & 0,32 & 0,8 & - & - & 0,000353 \\
\hline 5 & $\mathrm{C}_{1-\mathrm{NS}_{1} \mathrm{SP}_{50}}$ & & & & & 50 & 1 & - & 3 & 0,2 & 0,8 & 0,4 & - & 0,000001 \\
\hline 6 & $\mathrm{C} 1-\mathrm{NS}_{4} \mathrm{SP}_{50}$ & & & & & 50 & 4 & - & 2 & 0,21 & 0,8 & 0,4 & - & 0,000003 \\
\hline 7 & $\mathrm{C} 1-\mathrm{NS}_{8} \mathrm{SP}_{50}$ & & & & & 50 & 8 & - & 4 & 0,2 & 0,8 & 0,4 & - & 0,000006 \\
\hline 8 & C1-NS $900 \mathrm{SP}_{50}$ & & & & & 50 & 900 & - & 2 & 0,2 & 0,8 & 0,4 & - & 0,000075 \\
\hline 9 & $\mathrm{C} 1-\mathrm{NC}_{35} \mathrm{SP}_{50}$ & & & & & 50 & - & 35 & 4 & 0,26 & 0,8 & 0,4 & 0,00003 & - \\
\hline 10 & $\mathrm{C} 1-\mathrm{NC}_{50} \mathrm{SP}_{50}$ & & & & & 50 & - & 50 & 3 & 0,28 & 0,8 & 0,4 & 0,00004 & - \\
\hline 11 & $\mathrm{C} 1-\mathrm{NC}_{100} \mathrm{SP}_{50}$ & & & & & 50 & - & 100 & 3 & 0,26 & 0,8 & 0,4 & 0,00011 & - \\
\hline 12 & 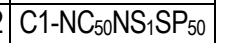 & & & & & 50 & 1 & 50 & 3 & 0,25 & 0,8 & 0,4 & 0,00004 & 0,000001 \\
\hline 13 & $\mathrm{C}-\mathrm{NC}_{50} \mathrm{NS}_{4} \mathrm{SP}_{50}$ & & & & & 50 & 4 & 50 & 3 & 0,26 & 0,8 & 0,4 & 0,00004 & 0,000003 \\
\hline 14 & C1-NC ${ }_{50} \mathrm{NS}_{8} \mathrm{SP}_{50}$ & & & & & 50 & 8 & 50 & 2 & 0,24 & 0,8 & 0,4 & 0,00004 & 0,000006 \\
\hline 15 & $\mathrm{C} 1-\mathrm{NC}_{25} \mathrm{NS}_{8} \mathrm{SP}_{50}$ & & & & & 50 & 8 & 25 & 3 & 0,25 & 0,8 & 0,4 & 0,00002 & 0,000006 \\
\hline 16 &  & & & & & 50 & 1 & 100 & 3 & 0,25 & 0,8 & 0,4 & 0,00008 & 0,000001 \\
\hline 17 & C1-NC ${ }_{100} N_{4} S_{4}$ & & & & & 50 & 4 & 100 & 2 & 0,26 & 0,8 & 0,4 & 0,00008 & 0,000003 \\
\hline 18 & $\mathrm{C} 1-\mathrm{NC}_{100} \mathrm{NS}_{8} \mathrm{SP}_{50}$ & & & & & 50 & 8 & 100 & 2 & 0,25 & 0,8 & 0,4 & 0,00008 & 0,000006 \\
\hline 19 & $\mathrm{C}_{2}-\mathrm{NC}_{50} \mathrm{NS}_{8} \mathrm{SP}_{50}$ & \multirow{5}{*}{445} & \multirow{5}{*}{820} & \multirow{5}{*}{ - } & \multirow{5}{*}{1035} & 50 & 8 & 50 & 21 & 0,32 & 1,0 & 0,5 & 0,00005 & 0,000008 \\
\hline 20 & $\mathrm{C}_{2}-\mathrm{NC}_{50} \mathrm{NS}_{1} \mathrm{SP}_{50}$ & & & & & 50 & 1 & 50 & 21 & 0,3 & 1,0 & 0,5 & 0,00005 & 0,000001 \\
\hline 21 & $\mathrm{C}_{2}-\mathrm{NC}_{300} \mathrm{NS}_{1} \mathrm{SP}_{50}$ & & & & & 50 & 1 & 300 & 22 & 0,28 & 1,0 & 0,5 & 0,00031 & 0,000001 \\
\hline 22 & $\mathrm{C}_{2}-\mathrm{NC}_{600} \mathrm{NS}_{1} \mathrm{SP}_{50}$ & & & & & 50 & 1 & 600 & 21 & 0,29 & 1,0 & 0,5 & 0,0006 & 0,000001 \\
\hline 23 & C2-NC $900 \mathrm{NS}_{1} \mathrm{SP}_{50}$ & & & & & 50 & 1 & 900 & 21 & 0,31 & 1,0 & 0,5 & 0,0009 & 0,000001 \\
\hline 24 & C3-NC $750 \mathrm{SP}_{40}$ & 400 & 820 & - & 1020 & 40 & - & 750 & 22 & 0,25 & 0,8 & 0,32 & 0,0006 & - \\
\hline 25 & $\mathrm{C}-\mathrm{NC}_{750} \mathrm{SP}_{40}$ & 445 & 820 & - & 1035 & 40 & - & 750 & 24 & 0,26 & 0,5 & 0,2 & 0,00038 & - \\
\hline 26 & $\mathrm{C}-\mathrm{NC}_{750} \mathrm{SP}_{40}$ & 460 & 950 & 880 & - & 40 & - & 750 & 53 & 0,28 & 0,5 & 0,2 & 0,00038 & - \\
\hline 27 & ${ }^{*} \mathrm{C} 6-\mathrm{NC}_{750} \mathrm{SP}_{40}$ & 485 & 800 & 825 & - & 40 & - & 750 & 64 & 0,25 & 0,8 & 0,32 & 0,0006 & - \\
\hline 28 & $\mathrm{C} 7-\mathrm{NC}_{600} \mathrm{NS}_{1} \mathrm{SP}_{40}$ & 445 & 820 & - & 1035 & 40 & 1 & 600 & 22 & 0,2 & 0,8 & 0,4 & 0,00048 & 0,000001 \\
\hline 29 & $\mathrm{CM}$ & 1300 & - & - & - & - & - & - & - & 0,26 & - & - & - & - \\
\hline 30 & $\mathrm{CM}-\mathrm{SP}_{50}$ & & & & & 50 & - & - & - & 0,21 & & 0,4 & - & - \\
\hline 31 & $\mathrm{CM}-\mathrm{NS}_{8} \mathrm{SP}_{50}$ & 1300 & & & & 50 & 8 & - & - & 0,21 & 08 & 0,4 & - & 0,000006 \\
\hline 32 & 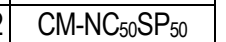 & 1300 & - & - & - & 50 & - & 50 & - & 0,21 & 0,8 & 0,4 & 0,00004 & - \\
\hline 33 & $\mathrm{CM}-\mathrm{NC}_{50} \mathrm{NS}_{8} \mathrm{SP}_{50}$ & & & & & 50 & 8 & 50 & - & 0,21 & & 0,4 & 0,00004 & 0,000006 \\
\hline
\end{tabular}

* C6-NC ${ }_{750} \mathrm{SP}_{40}$ в состав сырьевой смеси входит 40 кг PCAM и 45 кг МКУ на 1 м бетонной смеси

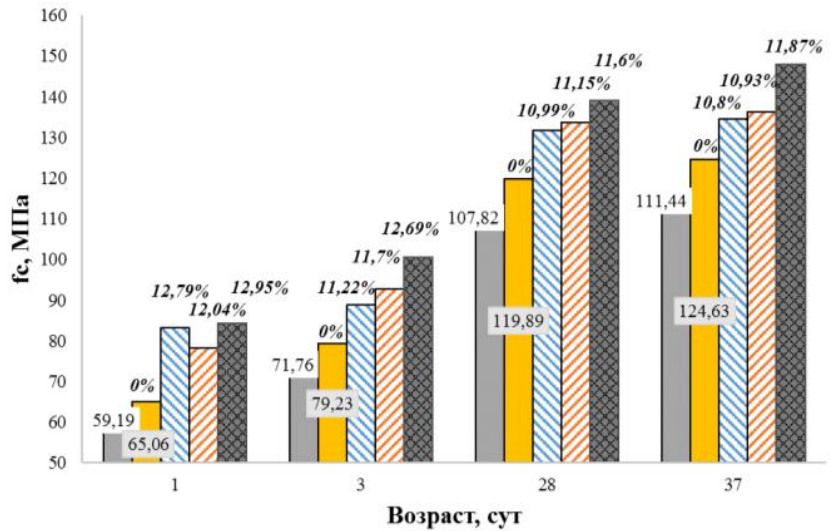

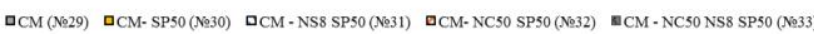

Рисунок 1 - Прочность при сжатии в зависимости от возраста цементных образцов (на графике указан \% увеличения прочности модифицированных образцов с нанодобавками, относительно образца, содержащего только СП)

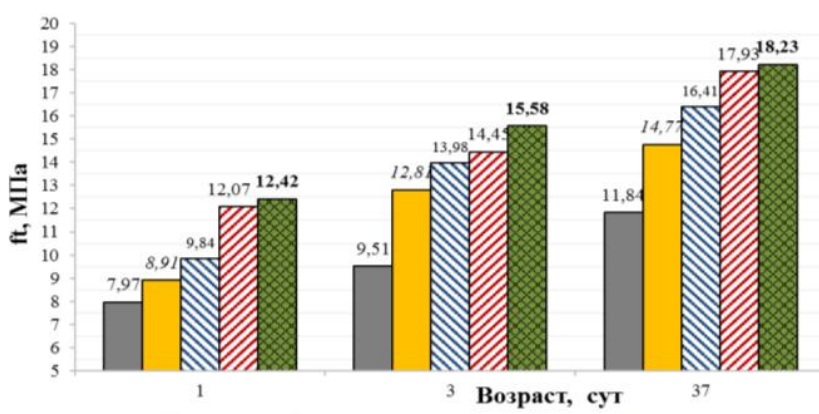

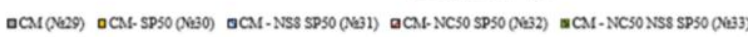

Рисунок 2 - Прочность при изгибе в зависимости от возраста цементных образцов

Кривые TG, DTG и DSC, полученные методом термогравиметрии для модифицированного и контрольного образцов цементного камня составов № 30 и 33 в возрасте 28 сут (рис. За, б) мало отличались по форме и положению эндотермических экстремумов. 
a)

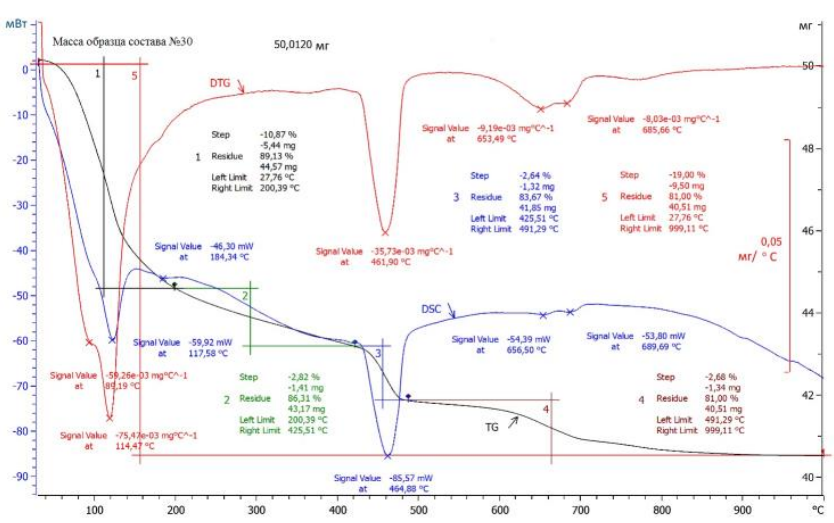

б)

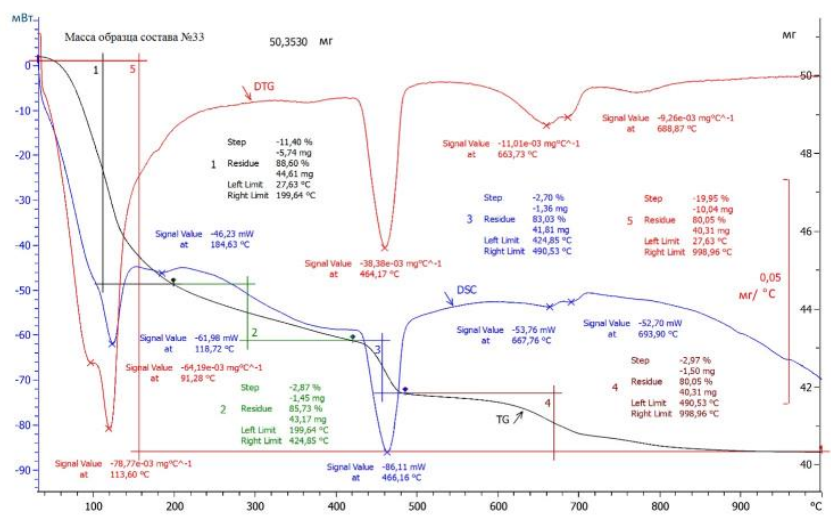

а) образец цементного камня состава № 30;

б) образец цементного камня состава № 33 .

\section{Рисунок 3 - Результаты термогравиметрии в возрасте 28 суток}

По данным термогравиметрии в возрасте 28 сут количество гидратной воды по интервальным потерям массы $20-400{ }^{\circ} \mathrm{C}$ было относительно больше на $4,5 \%$ в образце состава № 33 (СП+ $\left.\mathrm{HЧ} \mathrm{SiO}_{2}+\mathrm{MУHT}\right)$ по сравнению с образцом состава № 30 (СП без НЧ), количество связанной воды, относящейся у портландиту, больше на $4,77 \%$, полное количество химически связанной воды - на 4,5 \% больше.

С помощью рентгенофазового анализа (РФА) получили количественные данные по концентрации основных клинкерных минералов портландцемента и продуктов их гидратации. Исследования были проведены в возрасте $4 x$ часов, 1 и 28 суток.

Совмещенные дифррактограммы образцов составов № 29-33 в возрасте 4 ч, 1 сут и 28 сут представлены на рисунках 4 (а - г) и не показали отличие в 1) положении и 2) высоте пиков основных клинкерных минералов и портландита.

Минеральные фазы на рисунках обозначены цифрами 1-5 и соответствуют: 1 - алит ( $\left.\mathrm{C}_{3} \mathrm{~S}\right), 2$ - сумма алита и белита $\left(\mathrm{C}_{3} \mathrm{~S}+\mathrm{C}_{2} \mathrm{~S}\right)$, 3 - кальций алюминат $\left(\mathrm{C}_{3} \mathrm{~A}\right), 4$ - портландит $\left(\mathrm{Ca}(\mathrm{OH})_{2}\right), 5$ - ГАК гидрат алюмината кальция.

Анализ дифрактограмм в малоугловой области углов $2 \theta=0-10$ градусов показал, что положение пиков и их высота для низкои высокоосновных гидросиликатов кальция CSH I, CSH II и тоберморитподобных фраз $\mathrm{Ca}_{5} \mathrm{Si}_{6} \mathrm{O}_{16}(\mathrm{OH}) 2{ }^{*} \mathrm{nH}_{2} \mathrm{O}$ отличаются во всех возрастах 4 ч, 1 сут и 28 сут. В образцах составов № 31-33, модифицированных наночастицами, содержание CSH I и тоберморитподобных фаз выше, чем в образцах составов № 29 и 30 в возрасте 1 сут и 28 сут. По сравнению с CSH II в CSH I и тоберморитподобных фазах отношение $\mathrm{Ca} / \mathrm{Si}$ в среднем ниже $(0,8-1,5)$, чем в CSH II $(\geq 1,5)$, соответственно, доля атома Si c координационным число 4 выше по отношению к атому Са (2), и выше упорядоченность структуры CSH-геля в образцах составов № 31-33.

\section{Строительство}

doi.org/10.36773/1818-1212-2021-125-2-27-34 a)

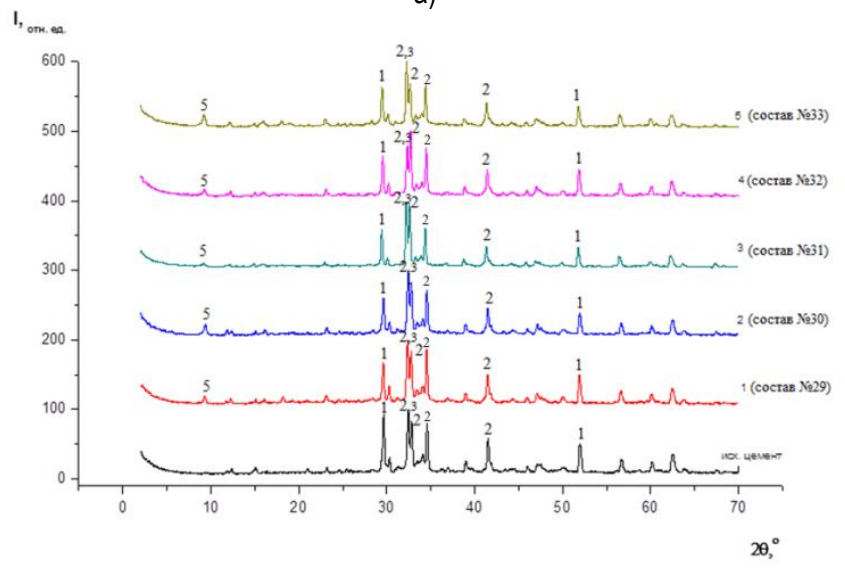

б)

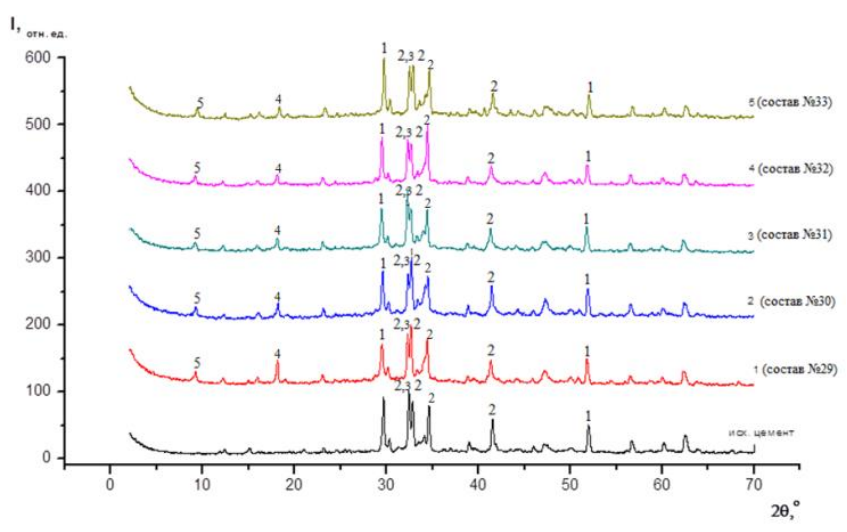

B)

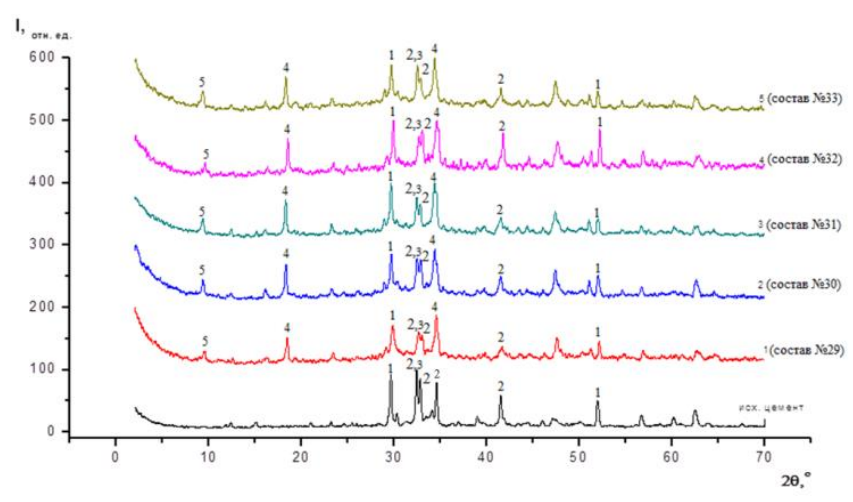

г)

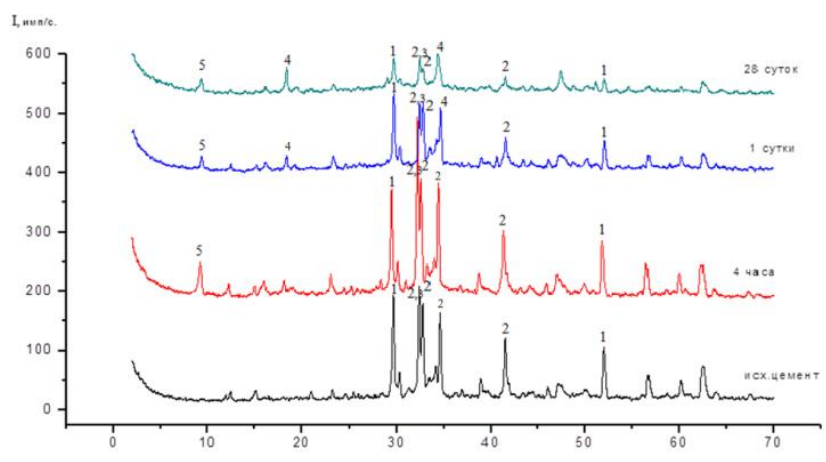

$2 \theta$

а) 4 часа твердения образцов; б) 1 сутки твердения образцов; в) 28 суток твердения образцов; г) образца состава № 33

Рисунок 4 - Совмещенные дифрактограммы образцов 
Для возраста 28 сут в дифрактограммах характерно появление тоберморитподобной структуры типа тоберморит 14 A, высота пиков которой значительно выше в образцах составов № 31-33 по сравнению с образцами составов № 29, 30. Это согласуется с результатами ИК-спектроскопии, которые показали более высокую степень поликонденсации-полимеризации кремнекислородных тетраэдрах в образцах составов № 31-33, модифицированных наночастицами, которая возрастала при переходе от возраста 1 сут к возрасту 28 сут, что соответствовало повышению упорядоченности структуры CSH-геля.

При использовании метода ИК-спектроскопии в возрасте 4 ч, 1 и 28 сут малые дозы наночастиц позволили выделить эффект влияния наночастиц на степень полимеризации CSH-геля отдельно от влияния на скорость образования геля CSH. При переходе от возраста 4 ч к 1 сут произошло смещение основного максимума алита в коротковолновую область $957 \mathrm{~cm}^{-1}$, что соответствовало формированию гидросиликатов с повышенной степенью поликонденсации кремнекислородного тетраэдра ККТ $n_{1}$. В возрасте 1 сут (рисунок 5) в диапазоне обратных длин волн $(1 / \lambda)=900-1100 \mathrm{~cm}^{-1}$ с помощью программы Ориджин выявлена точка перегиба в районе $987-989$ см $^{-1}$ соответствующая гидросиликатам кальция с повышенной степенью поликонденсации кремнекислородного тетраэдра п2. По значениям нормализованных интенсивностей в точке перегиба определено, что содержание гидросиликатов кальция с повышенной степенью поликонденсации п2 в образцах составов № 31-33, модифицированных наночастицами, на 18-22,1 \% выше по сравнению с образцом состава № 30 (СП, без НЧ). По значениям коэффициента К, представляющего отношение нормализованных интенсивностей в основном максимуме и в точке перегиба, оценили, доля гидросиликатов кальция со степенью поликонденсации $\mathrm{n}_{2}$ по отношению к гидросиликатам с $n_{1}$ в образце состава № $31\left(\mathrm{HU} \mathrm{SiO}_{2}\right)$ и в образце состава № 33 (HЧ $\mathrm{SiO}_{2}+$ МУНТ) были существенно выше на $12,6 \%$ по сравнению с образцом составов № 30, модифицированным только СП.

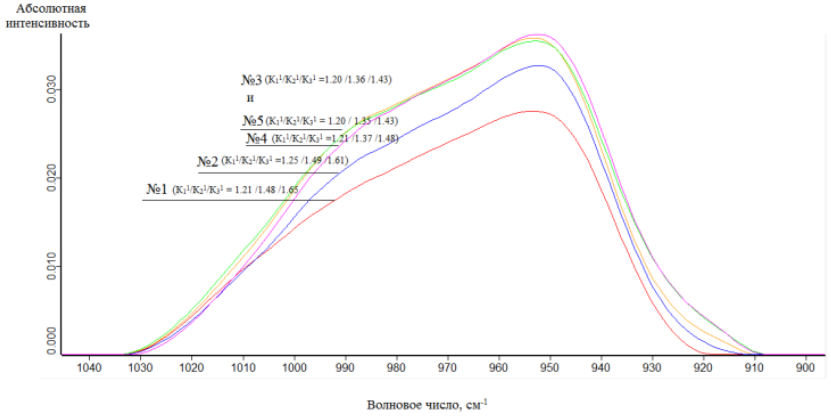

образец № 1 - состав № 29 (красный); образец № 2 - состав № 30 (синий), образец № 3 - состав № 31 (зеленый), образец № 4 - состав № 32 (розовый), образец № 5 - состав № 33 (оранжевый)

Рисунок 5 - Сравнение контура полосы поглощения валентных колебаний кремнекислородного тетраэдра гидратированных в течение 1 суток по абсолютным интенсивностям

Для возраста 28 сут в ИК-спектрах образцов № 29-33 (рисунок 6) выделены две точки перегиба в районе 993-996 см-1, 1016-1018 см-1, расположенные в более коротковолновой области по сравнению С точкой перегиба в возрасте 1 сут. Это указывало на переход гидросиликатов со степенями поликонденсации кремнекислородных тетраэдров, близкими к 1, наблюдавшихся в ИК-спектрах в возрасте 1 сут, за счет их объединения в структуры с более высокой степенью поликонденсации (28 сут). По отношению абсолютных интенсивностей в основном максимуме содержания гидросиликатов кальция со степенью поликонденсации $n_{1}$ в образце состава № $31\left(\mathrm{C}\right.$ + $\left.\mathrm{HЧ}_{\text {SiO}}\right)$ было выше по сравнению с образцом состава № 30 (СП, без НЧ) на $14,6 \%$. Содержание гидросиликатов кальция со степенью поликонденсации $n_{4}$, соответствующей первой точке перегиба, в образцах состава № 31 (СП + $\mathrm{HU} \mathrm{SiO}_{2}$ ), № 32 (СП + НЧ МУНТ) по сравнению с образцом состава № 30 было выше на 18,1; 10,4 \%. По величине коэффициента $K_{1}$ отношение содержаний гидросиликатов со степенью поликонденсации $n_{4}$ и $n_{1}$ для образца состава № 33 было выше для образца состава № 30 на 20 \% (12,6\% в возрасте 1 сут) вследствие более высокой скорости поликонденсации ККТ кремнекислородных тетраэдров в образцах, модифицированных комбинацией наночастиц $\left(\mathrm{SiO}_{2}+\mathrm{MYHT}\right)$. Содержание гидросиликатов кальция со степенью поликонденсации кремнекислородных тетраэдров $n_{5}$, соответствующих второй точке перегиба, было выше на 13, 3 \% в образце состава № 31 по сравнению с образцом 30. По величине коэффициента $K_{2}$ доля гидросиликатов кальция со степенью поликонденсации ККТ $n_{5}$ по отношению к гидросиликатам со степенью поликонденсации $n_{1}$ выше на 24,4 \% в образце № 33 по сравнению с образцом вследствие ускорения кинетики поликонденсации ККТ и образования структур с повышенной степенью поликонденсации $n_{5}$ в присутствии комбинации наночастиц $\mathrm{SiO}_{2}+$ МУНT.

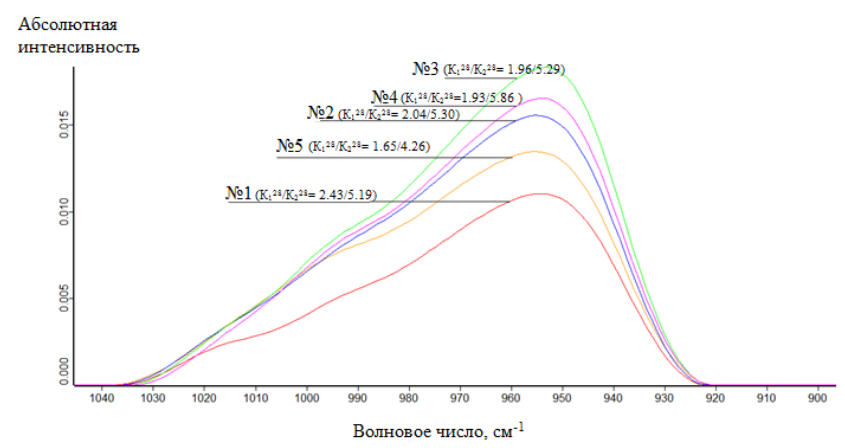

образец № 1 - состав № 29 (красный); образец № 2 - состав № 30 (синий), образец № 3 - состав № 31 (зеленый), образец № 4 - состав

№ 32 (розовый), образец № 5 - состав № 33 (оранжевый)

Рисунок 6 - Сравнение контура полосы поглощения валентных колебаний кремнекислородного тетраэдра по абсолютным интенсивностям гидратированных 28 суток по абсолютным интенсивностям

Для ультразвуковых измерений были использованы: ультразвуковой прямоугольный приемник квадратных волн модели 50777PR, который в сочетании с осциллографом и соответствующими ӥ-образными датчиками обеспечивал ультразвуковые возможности измерения (далее прибор 1) с используемой частотой 5 МГц и прибор ПУЛЬСАР-2.2 (далее прибор 2) с используемой частотой 0,05 МГц.

a)

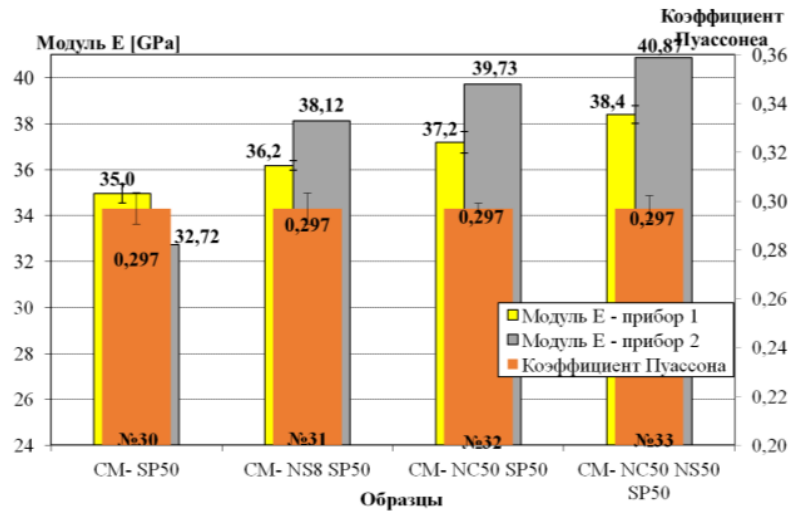

б)

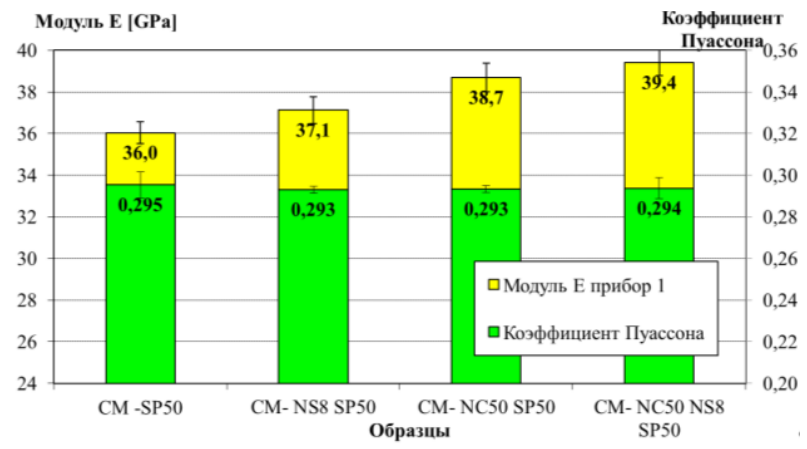

а) по приборам 1 и 2 в возрасте 40 сут;

б) по прибору 1 в возрасте 5 месяцев

Рисунок 7 - Модуль упругости $\mathrm{E}$ и коэфффициент Пуассона на основе данных 
По результатам получены повышения модулей Юнга и сдвига, а также плотности модифицированных образцов состава № 30-33 в возрасте 1 мес. и 5 мес. (рис. 7а, б). Максимальное увеличение указанных параметров (до 10 \%) наблюдалось у образцов, модифициированных

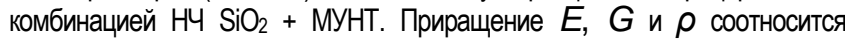
с повышением $f_{c}$ и $f_{t}$. Повышение плотности $\rho$ дополнительно указывает на изменение поровой структуры цементного камня и структуры геля CSH.

Методом наноиндентированием была объяснена ранее установленная разность прочности при сжатии $f_{c}$ между контрольным образцом № 30 и модифицированными образцами № 31, 32 и 33. Результаты деконволюции гистограмм распределения объема по приведенному модулю упругости М и жесткости Н по трем фразам - экспоненциальным функциям Гаусса представлены, а также значения модуля Юнга, твердости и доля фазы для цементных образцов представлены на рисунках 8 а-г.

Средние значения модуля упругости $\mathrm{M}$ и жесткости $\mathrm{H}$, вычисленные как сумма произведений среднего значения $\mathrm{M}, \mathrm{H}$ в каждой фазе на ее объемную долю, для образцов составов № 30-33 имели значения: 1 - 18,00 ГПа, 1,32 ГПа; 2 - 39,79 ГПа, 1,40 ГПа; 3 - 29,13 ГПа 1,14 ГПа; 4 - 32,14, 1, 49 ГПа. Средние по объему значения М, H в образцах составов № 31-33, модифицированных наночастицами, были выше, чем в образце состава № 30 .

Полученные результаты показывают, что гистограммы распределения объема по приведенному модулю упругости М и жесткости $\mathrm{H}$ в образцах составов № 31, 32, 33 сдвинулись в область больших средних значений по сравнению с образцом состава №30 (рис. 8а, б). При этом уменьшилась объемная доля фазы 1 с меньшими средними значениями М и Н и возросла объемная доля фаз 2 и 3 с большими средними значения М, Н и с более плотной объемной упаковкой частиц геля $\mathrm{CSH}$.

Для фаз 1, 2, 3 распределения по М и для фазы 3, имеющей максимальное среднее значение $\mathrm{H}$ распределения по Нв образцах составов № 31, 32, 33 уменьшилась ширина распределения по соответствующей функции Гаусса, что характеризуется уменьшением отношения StdDev/Mcp, Hcp (StdDev - показатель в экспоненте функции Гаусса) и показывает более высокую структурную упорядоченность геля CSH в образцах, модифицированных наночастицами.

а)

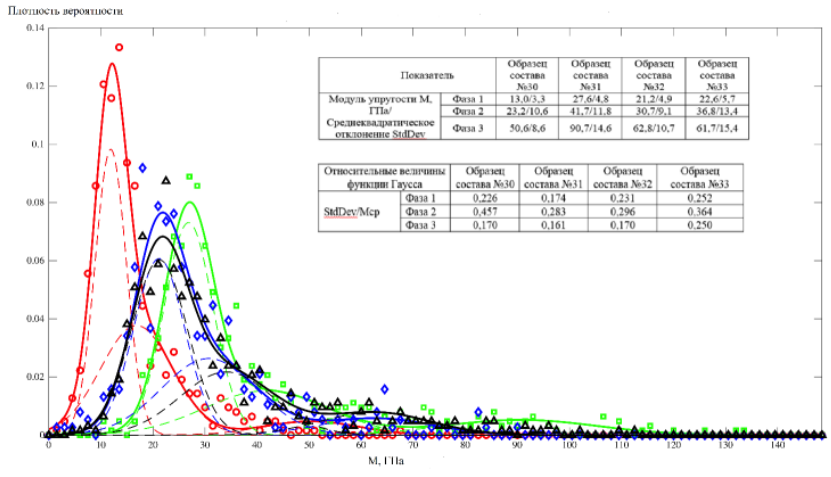

б)

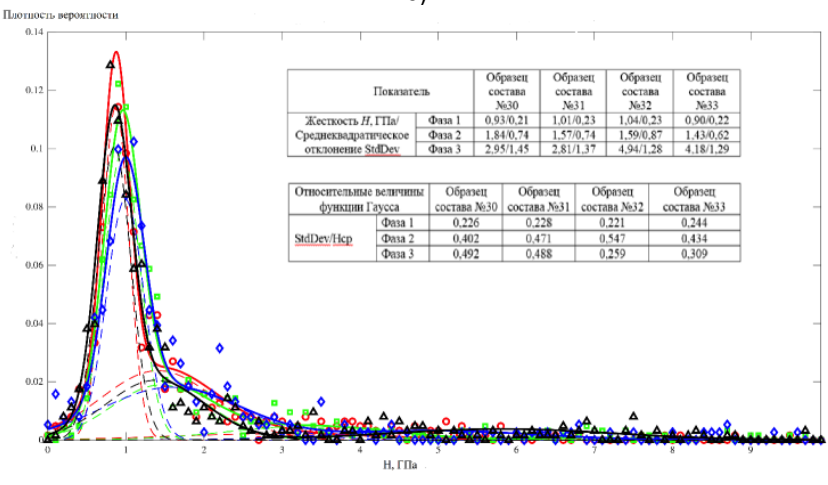

а) по модулю упругости М и б) по твердости $\mathrm{H}$ - для образцов в возрасте 4 месяца составов № 30 (красный); № 31 (зеленый); № 32 (синий); № 33 (черный)

Рисунок 8 - Гистограммы распределения точек наноиндентирования Строительство doi.org/10.36773/1818-1212-2021-125-2-27-34
Методом наноиндентирования установлено существенное смещение объемной доли фаз CSH геля в область больших средних значений М и Н и уменьшение отношения StDev/M, Н для выделенных фаз, что свидетельствует большей плотности упаковки частиц геля, более высокой структурированности вещества геля, и может быть соотнесено с различиями характеристик $\left(E, G, \rho, f_{c}, f_{c t}\right)$.

Установлена оптимальная дозировка всех компонентов комплексной добавки, которая приводит к синергетическому эффекту, т. е. к улучшению макрохарактеристик бетона за счет направленного влияния наночастиц на структуру бетона.

Эксперименты с тяжелым бетоном показали повышение механических и физических характеристик в диапазоне малых доз наночастиц (МУНТ + $\left.\mathrm{SiO}_{2}\right)$, вводимых в количестве 0,5-1,0 \% по цементу и значений В/Ц $=0,15-0,35$.

Обобщенные результаты механических испытаний раздельного и совместного действия наночастиц представлены на рисунке 9.

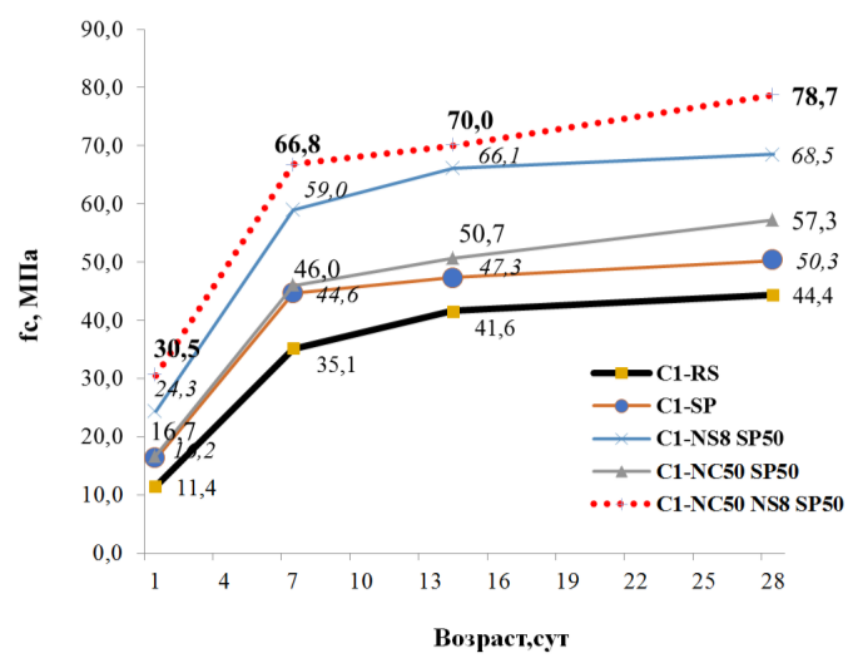

Рисунок 9 - Влияние комплексной добавки на прочностные характеристики тяжелого бетона

Из рисунка 9 следует, что использование поликарбоксилатного суперпластификатора (состав № 2) приводит к повышению прочности на сжатие на $10 \%$, а при совместном использовании с гидротермальным нанокремнеземом (состав № 7) или с наночастицами МУНТ (состав № 10) приводит к повышению прочностных показателей, превышающих показатели бездобавочного бетона на 28-е сутки до $25 \%$. При использовании совместно всех компонентов добавки в проектном возрасте прочность состава № 14 возросла до 77 \% по сравнению с бездобавочным составом.

Приращение прочности бетона при сжатии в случаи применения комбинации наночастиц $\mathrm{SiO}_{2}$ и МУНТ превышало сумму приращений прочности при сжатии вводе наночастиц $\mathrm{SiO}_{2}$ и МУНТ отдельно в возрасте 1 сут - на $66 \%, 7$ сут - $52 \%, 28$ сут - 12,7\%.

Влияние комплексной добавки на бетонные смеси удобоукладываемостью П5 (ОК = 21-25 см) оценивалось прочностью бетона на сжатие в возрасте 1-е, 7-е, 14-е и 28-е сутки. Результаты испытаний бетона испытаний бетона с комплексной добавкой составов № 19-23 представлены в таблице 2.

Таблица 2 - Результаты механических испытаний бетона (ОК=21-25 см)

\begin{tabular}{|c|c|c|c|c|c|c|}
\hline \multirow[b]{2}{*}{ № состава } & \multirow{2}{*}{$\begin{array}{c}\text { Количество вводимой } \\
\text { добавки от массы } \\
\text { цемента, \% }\end{array}$} & \multirow[b]{2}{*}{ B/L } & \multicolumn{4}{|c|}{ Прочность на сжатие, МПа } \\
\hline & & & 1 сут & 7 сут & 14 сут & $28 c$ \\
\hline 19 & 1,0 & 0,32 & 15,8 & 51,8 & 59,2 & 63,5 \\
\hline 20 & 1, & 0,3 & 14,0 & 53,5 & 62,2 & 64,0 \\
\hline 21 & 1, & 0,28 & 14,2 & 55,1 & 64,4 & 65,4 \\
\hline 22 & 1,0 & 0,29 & 14,3 & 52,4 & 64,2 & 69,0 \\
\hline 23 & 1,0 & 0,31 & 14,2 & 52,2 & 59,1 & 68,1 \\
\hline
\end{tabular}

Бетон состава № 22, включавший комплексную добавку в количестве $1 \%$ от массы цемента, обеспечил требуемый класс по подвижности и удобоукладываемости бетонной смеси П5 и сохранении 
удобоукладываемости в течение 2 ч, необходимый в том числе для перекачки по вертикали под давлением по бетонопроводам и заливки в узкие формы и в формы с арматурой, при относительно низком В/Ц $=0,29$ и, соответственно, самой высокой прочности при сжатии в составах № 19-23.

Исследование прочности, трещиностойкости и долговечности конструкционного бетона, модифицированного пластифицирующей добавкой, содержащей в своем составе наноматериалы, в ходе лабораторных, предпроизводственных и производственных замесов осуществлялись в аккредитованной строительной лаборатории Генподрядчика по строительству Белорусской Атомной Электростанции (БелАЭС).

При вводе в бетонную смесь комплексной добавки, содержащей 750 г/т, НЧ МУНТ достигали подвижности по удобоукладываемости класса П5 при сохранности 120 мин, для самоуплатняющихся смесей - Р4-Р6 при сохранности 120 мин класса по вязкости, определяемые по времени Т500 (времени, необходимому для расплыва стандартного конуса бетонной смеси до диаметра 500 мм) - VS1 1,5-4,0, класса по способности бетонной смеси преодолевать препятствия, определяемые способностью преодолевать сопротивление арматурных стержней в L-образном ящике - PA1 0,2-0,6, класса по устойчивости к расслаиванию, определяемые при испытании бетонной смеси на устойчивость к расслаиванию с использованием сита SR1 2,0\%.

В производственных замесах произведены и испытаны образцы составов № 24-28 (с В/Ц = 0,2 - 0,28) на прочность при сжатии, прочность на осевое растяжение, морозостойкость, водонепроницаемость, водопоглощение, пористость, в том числе неразрушающими методами и получены следующие выводы:

- прочность бетона при осевом растяжении доводили до 2,85 МПа;

- прочность бетона на четырехточечный изгиб от 5,18 до 7,99 МПа;

- коэффициент пористости $\lambda$ повышали до 0,88; коэффрициент однородности дифференциального распределения пор по диаметрам $\alpha$ до 0,4; капиллярную пористость в диапазоне 4,5-5,35 \%;

- повышение марки бетона по водонепроницаемости с W8 до W20;

- марка по морозостойкости бетона до F500;

- трещиностойкость бетона по значениям коэффициентов $K_{1 c}$ при нормальном отрыве и К2с при поперечном сдвиге была для варианта ввода комбинации наночастиц $\mathrm{SiO}_{2}$ и МУНТ по сравнению с вариантом ввода наночастиц МУНТ отдельно: коэффициент $K_{1} c$ был в 3,29/2,15=1,53 раза выше.

\section{Заключение}

1. Обоснована эффрективность применения комплексной нанодобавки с комбинацией наночастиц (МУНТ+ГНК) в диапазоне малых доз 1000-10000 раз ниже традиционно изученных с эффректом взаимно усиленного влияния на структуру геля гидросиликатов кальция, что обуславливает повышение механических и физических характеристик тяжелого портландцементного бетона [20-35].

2. Экспериментально обоснован механизм повышения прочности модифицированных цементных композитов:

- по РФА - комплексная добавка способствуют повышению доли низкоосновных гидросиликатов кальция $\mathrm{CSH}(\mathrm{I})$ и томберитподобных структур с пониженными значениями отношения $\mathrm{Ca} / \mathrm{S}$ в составе фаз CSH-геля, повышению упорядоченности структуры наночастиц и фаз СSH-геля;

- ИК спектральным анализом за счет повышения скорости и степени полимеризации-поликонденсации кремнекислородных тетраэдров - продуктов гидратации алита, приводящей к повышению упорядоченности и однородности структуры, формы частиц $\mathrm{CSH}$-геля и самого CSH-геля;

- методом наноиндентирования - повышением модуля упругости и твердости CSH-геля, которые прямо пропорциональны объемной плотности упаковки наночастиц;

- при испытаниях на трещиностойкость - изменение значений коэфффициентов интенсивности напряжений.

3. Снижение доли в комплексной добавке углеродных наночастиц, путем частичной замены их более дешевыми по себестоимости наночастицами $\mathrm{SiO}_{2}$.

\section{Список цитированных источников}

1. Sobolev, K. Engineering of $\mathrm{SiO}_{2}$ Nanoparticles for Optimal Performance in Nano Cement-Based Materials / K. Sobolev [et al.] // Nanotechnology in Construction 3. - 2009. - pp. 139-148.

2. Sobolev, K. How Nanotechnology Can Change the Concrete World / K. Sobolev, M. Ferrada Gutierrez // American Ceramic Society Bulletin, 2009. - pp. 113-116.

3. Sobolev, K. How Nanotechnology Can Change the Concrete World / K. Sobolev, M. Ferrada Gutierrez // American Ceramic Society Bulletin, 2009. - pp. 117-120.

4. Sobolev, K., Torres-Martinez L.M. Nanomaterials and nanotechnology for high-performance cement composites/ K. Sobolev, I. Flores, R. Hermosillo, L. M. Torres-Martínez // Proceedings of ASI Session on «Nanotechnology Concrete: Recent Developments and Future Perspectives», 2006. - pp. 117-120.

5. Sanchez, F. Nanotechnology in concrete - A review / F. Sanchez, K. Sobolev// Construction and Building Materials. - 2010. - Vol. 24, № 5. - pp. 2060-2071.

6. Гуриненко, Н. С. Технология и свойство бетона с полифункциональной добавкой, содержащей ультрадисперсный микрокремнезем: авторефрерат диссертации на соискание ученной степени кандидата технических наук: 05.23.05 / Н. С. Гуриненко; Белорусский национальный технический университет. - Минск, 2020. 25 c.

7. Witkowski, H. Air purifying pavement: development of photocatalytic concrete blocks / H. Witkowski [et al.] // Applied Sciences. - 2019. Vol. 9, № 9. - p. 1735.

8. Zhang, P. Influence of nano-SiO 2 on properties of fresh and hardened high performance concrete: A state-of-the-art review / P. Zhang, J. Wan, K. Wang, Q.Li// Construction and Building Materials. - 2017. -Vol. 148, № 1. - pp. 648-658.

9. Zhang P. Durability of Steel Fiber-Reinforced Concrete Containing SiO2 Nano-Particles / P. Zhang [et al.] // Materials. - 2019. - Vol. 12, № 13. - pp. 2184 .

10. Рябчиков, П. В. Технология и физико-технические свойства тяжелого бетона, модифицированного углеродными наноматериалами: автореферат диссертации на соискание ученной степени кандидата технических наук: 05.23.05 / П. В. Рябчиков; Белорусский национальный технический университет. - Минск, 2017. $28 \mathrm{c}$.

11. Singh, L. P. Studies on early stage hydration of tricalcium silicate incorporating silica nanoparticles: part II / L.P. Singh [et al.] // Construction and Building Materials . -2016. - Vol. 2, № 1. - pp. 943-949.

12. Kiran Kumar, N. L. N. Effects of nano silica on the strengths of geopolymer concrete cured at ambient temperature / N .L. N. Kiran Kumar, K.V.S. Gopala Krishna Sastry // International Journal of Civil Engineering and Technology. -2017. - Vol. 8, № 8. - pp. 437-444.

13. R. B. Ardalan, N. Jamshidi, H. Arabameri, A. Joshaghani, M. Mehrinejad, $P$. Sharafi. Enhancing the permeability and abrasion resistance of concrete using colloidal nano-SiO 2 oxide and spraying nanosilicon practices / R. B. Ardalan [et al.] // Construction and Building Materials. 2017. - Vol. 146. - pp. 128-135.

14. Khaloo, A. Influence of different types of nano-SiO 2 particles on properties of high-performance concrete/ A. Khaloo, M.H. Mobini, P. Hosseini. // Construction and Building Materials. - 2016. - Vol. 113. pp. 188-201.

15. Potapov, V. V. Obtaining sols, gels and mesoporous nanopowders of hydrothermal nanosilica / V. V. Potapov, R. Fediuk, D.S. Gorev // Journal of Sol-Gel Science and Technology. -2020. - Vol. 94, № 3. pp. 681-694.

16. Flores-Vivian, I. The effect of $\mathrm{SiO}_{2}$ nanoparticles derived from hydrothermal solutions on the performance of portland cement based materials / I. Flores-Vivian [et al.] // Frontiers of Structural and Civil Engineering. - 2017. - Vol. 11. - pp. 436-445.

17. Shah, et al. Highly-dispersed carbon nanotube-reinforced cementbased materials United States Patent 9,365,456. June 14, 2016.

18. Shah, et al. Highly dispersed carbon nanotube-reinforced cementbased materials. United States Patent 9,499,439. November 22, 2016

19. Fulton, et al. Methods and systems for making nanocarbon particle admixtures and concrete. United States Patent 10,584,072. March 10, 2020 
20. Потапов, В. В. Модифицирование гидротермальным нанокремнеземом материалов на основе цемента / В. В. Потапов, Е. Н. Грушевская, С. Н. Леонович / Строительные материалы. 2017. - С. 4-9.

21. Хрусталев, Б. М. Композиционные материалы на основе цементных вяжущих, модифицированных нанодобавками $\mathrm{SiO}_{2} /$ Б. М. Хрусталев, С. Н. Леонович, В. В. Потапов, Е.Н. Грушевская // Наука и техника. - 2017. - Т. 16, № 6. - С. 459-465.

22. Жданок, С. А. Повышение прочности бетона пластифицирующей добавкой на основе наноструктурированного углерода / С. А. Жданок [и др.] // Строительные материалы. - 2018. - № 6. C. $67-72$.

23. Полонина, Е. Н. / Физико-механические характеристики нанобетона / Е. Н. Полонина, С. Н. Леонович, Е.А.Коледа// Научно электронный журнал «Вестник Инженерной школы Дальневосточного федерального университета». - 2018. - № 4(37). C. 100-111.

24. Жданок, С. А. Влияние пластифицирующей добавки, содержащей углеродный наноматериал, на свойства самоуплотняющегося бетона / С. А. Жданок [и др.] // Вестник гражданских инженеров Санкт-Петербургский государственный архитектурностроительный университет. - 2018. - №6 (71). - С. 76-85.

25. Коледа, Е. А. Физико-механические свойства бетона средней прочности модифицированного углеродной наноструктурированной добавкой / Е. А. Коледа [и др.] // Вестник Поволжского государственного технологического университета. Сер.: Материалы. Конструкции. Технологии. - 2018. - № 2(6). - С. 24-34.

26. Жданок, С. А. Физико-механические характеристики бетона, модифицированного пластифицирующей добавкой на основе наноструктурированного углерода / С. А. Жданок [и др.] // Инженернофризический журнал. - 2019. - Том 92, № 1 (январь-февраль). C. 14-20.

27. Жданок, С. А. Влияние пластифицирующей добавки на основе наноструктурированного углерода в самоуплотняющейся бетонной смеси на ее технологические свойства / С. А. Жданок [и др.] // Инженерно-физический журнал. - 2019. - Том 92, № 2 (мартапрель). - С. 391-396.

28. Zhdanok, S. A. Physicomechanical Characteristics of Concrete Modified by a anostructured-Carbon-Based Plasticizing Admixture. I S. A. Zhdanok [et al.] // Journal of Engineering Physics and Thermophysics. - 2019. - Vol. 92, №. 1. - pp. 14-20.

29. Zhdanok, S. A. Influence of the Nanostructured-Carbon-Based Plasticizing Admixture in a Self-Compacting Concrete Mix on Its Technological Properties/S. A. Zhdanok [et al.] // Journal of Engineering Physics and Thermophysics. - 2019. - Vol. 92, №. 2. - C. 376-382.

30. Жданок, С. А. Модификация цементных бетонов добавками, содержащими наноразмерные материалы / С. А. Жданок [и др.] // Инженерно-физический журнал. - 2020. - Том 93, № 3 (майиюнь). - С. 669-673.

31. Zhdanok, S. A. Modification of Cement Concrete by Admixtures Containing Nanosized Materials / S. A. Zhdanok, V. V. Potapov, E. N. Polonina, S. N. Leonovich //Journal of Engineering Physics and Thermophysics. - 2020. - Vol. 93, №. 3. - pp. 669-673.

32. Жданок, С. А. Прочность нанофибробетона на растяжение / С. А. Жданок [и др.] // Инженерно-физический журнал. - 2020. Том 93, № 4 (июль-август). - С.1051-1055.

33. Жданок, С. А. Исследование методом ИК-спектроскопии степени активации углеродных наноматериалов для модифицирования конструкционного бетона / С. А. Жданок, Е. Н. Полонина, С. Н. Леонович // Строительные материалы. - 2020. - № 7. - С. 49-53.

34. Полонина, Е. Н. Механизм повышения прочности цементно-водных образцов, модисрицированных наночастицами $\mathrm{SiO}_{2}$ и МУНТ / Е. Н. Полонина [и др.] // Инженерно-физический журнал. - 2021. Том 94, № 1 (январь-фревраль). - С. 72-83.

35. Polonina, E. N. Mechanism for Improving the Strength of a Cement Material Modified by $\mathrm{SiO}_{2}$ Nanoparticles and Multiwall Carbon Nanotubes / E. N. Polonina, V. V. Potapov, S. A. Zhdanok S. N. Leonovich // Journal of Engineering Physics and Thermophysics. - 2021. - Vol. 94, №. 1. - pp. 67-78.

\section{References}

1. Sobolev, K. Engineering of SiO2 Nanoparticles for Optimal Performance in Nano Cement-Based Materials / K. Sobolev [et al.] // Nanotechnology in Construction 3. - 2009. - pp. 139-148.

2. Sobolev, K. How Nanotechnology Can Change the Concrete World/ K. Sobolev, M. Ferrada Gutierrez // American Ceramic Society Bulletin, 2009. - pp. 113-116.

3. Sobolev, K. How Nanotechnology Can Change the Concrete World / K. Sobolev, M. Ferrada Gutierrez // American Ceramic Society Bulletin, 2009. - pp. 117-120.

4. Sobolev, K., Torres-Martinez L.M. Nanomaterials and nanotechnology for high-performance cement composites/ K. Sobolev, I. Flores, R. Hermosillo, L. M. Torres-Martínez // Proceedings of ASI Session on «Nanotechnology Concrete: Recent Developments and Future Perspectives», 2006. - pp. 117-120.

5. Sanchez, F. Nanotechnology in concrete - A review / F. Sanchez, K. Sobolev // Construction and Building Materials. - 2010. - Vol. 24, №5. - pp. 2060-2071.

6. Gurinenko, N. S. Tekhnologiya i svojstvo betona s polifunkcional'noj dobavkoj, soderzhashchej ul'tradispersnyj mikrokremnezem: avtoreferat dissertacii na soiskanie uchennoj stepeni kandidata tekhnicheskih nauk: 05.23.05 / N. S. Gurinenko; Belorusskij nacional'nyj tekhnicheskij universitet. - Minsk, 2020. - $25 \mathrm{~s}$.

7. Witkowski, H. Air purifying pavement: development of photocatalytic concrete blocks / H. Witkowski [et al.] // Applied Sciences. - 2019. Vol. 9, № 9. - p. 1735.

8. Zhang, P. Influence of nano-SiO2 on properties of fresh and hardened high performance concrete: A state-of-the-art review / P. Zhang, J. Wan, K. Wang, Q.Li// Construction and Building Materials. - 2017. Vol. 148, № 1. - pp. 648-658.

9. Zhang P. Durability of Steel Fiber-Reinforced Concrete Containing SiO2 Nano-Particles / P. Zhang [et al.] // Materials. - 2019. Vol. 12, № 13. - pp. 2184.

10. Ryabchikov, P.V. Tekhnologiya i fiziko-tekhnicheskie svojstva tyazhelogo betona, modificirovannogo uglerodnymi nanomaterialami: avtoreferat dissertacii na soiskanie uchennoj stepeni kandidata tekhnicheskih nauk: 05.23.05 / P. V. Ryabchikov; Belorusskij nacional'nyj tekhnicheskij universitet. - Minsk, 2017. - 28 s.

11. Singh, L. P. Studies on early stage hydration of tricalcium silicate incorporating silica nanoparticles: part II / L.P. Singh [et al.] // Construction and Building Materials. - 2016. - Vol. 2, № 1. - pp. 943-949.

12. Kiran Kumar, N. L. N. Effects of nano silica on the strengths of geopolymer concrete cured at ambient temperature / N .L. N. Kiran Kumar, K.V.S. Gopala Krishna Sastry // International Journal of Civil Engineering and Technology. - 2017. - Vol. 8, № 8. - pp. 437-444.

13. R. B. Ardalan, N. Jamshidi, H. Arabameri, A. Joshaghani, M. Mehrinejad, P. Sharafi. Enhancing the permeability and abrasion resistance of concrete using colloidal nano-SiO2 oxide and spraying nanosilicon practices / R.B. Ardalan [et al.] // Construction and Building Materials. - 2017. - Vol. 146. - pp. 128-135.

14. Khaloo, A. Influence of different types of nano-SiO2 particles on properties of high-performance concrete/ A. Khaloo, M. H. Mobini, P. Hosseini. // Construction and Building Materials. - 2016. - Vol. 113. pp. 188-201.

15. Potapov, V. V. Obtaining sols, gels and mesoporous nanopowders of hydrothermal nanosilica / V. V. Potapov, R. Fediuk, D. S. Gorev // Journal of Sol-Gel Science and Technology. -2020. - Vol. 94, № 3. pp. 681-694.

16. Flores-Vivian, I. The effect of $\mathrm{SiO} 2$ nanoparticles derived from hydrothermal solutions on the performance of portland cement based materials / I. Flores-Vivian [et al.] // Frontiers of Structural and Civil Engineering. - 2017. - Vol. 11. - pp. 436-445.

17. Shah, et al. Highly-dispersed carbon nanotube-reinforced cementbased materials United States Patent 9,365,456. June 14, 2016.

18. Shah, et al. Highly dispersed carbon nanotube-reinforced cementbased materials. United States Patent 9,499,439. November 22, 2016.

19. Fulton, et al. Methods and systems for making nanocarbon particle admixtures and concrete. United States Patent 10,584,072. March 10, 2020 
Вестник Брестского государственного технического университета. 2021

20. Potapov, V. V. Modificirovanie gidrotermal'nym nanokremnezemom materialov na osnove cementa / V. V. Potapov, E. N. Grushevskaya, S. N. Leonovich / Stroitel'nye materialy. - 2017. - S. 4-9.

21. Hrustalev, B. M. Kompozicionnye materialy na osnove ce-mentnyh vyazhushchih, modificirovannyh nanodobavkami $\mathrm{SiO} 2$ / B. M. Hrustalev, S. N. Leonovich, V. V. Potapov, E.N. Grushev-skaya // Nauka i tekhnika. - 2017. - T. 16, № 6. - S. 459-465.

22. Zhdanok, S. A. Povyshenie prochnosti betona plastificiruyushchej dobavkoj na osnove nanostrukturirovannogo ugleroda / S. A. Zhdanok [i dr.] // Stroitel'nye materialy. - 2018. - № 6. - S. 67-72.

23. Polonina, E. N. / Fiziko-mekhanicheskie harakteristiki nanobetona / E. N. Polonina, S. N. Leonovich, E. A. Koleda // Nauchno elektronnyj zhurnal «Vestnik Inzhenernoj shkoly Dal'nevostochnogo federal'nogo universiteta». - 2018. - № 4(37). - C. 100-111.

24. Zhdanok, S. A. Vliyanie plastificiruyushchej dobavki, soderzha-shchej uglerodnyj nanomaterial, na svojstva samouplotnyayushchegosya betona / S. A. Zhdanok [i dr.] // Vestnik grazhdanskih inzhenerov Sankt-Peterburgskij gosudarstvennyj arhitekturno-stroitel'nyj universitet. - 2018. - №6 (71). - C. 76-85.

25. Koleda, E. A. Fiziko-mekhanicheskie svojstva betona srednej prochnosti modificirovannogo uglerodnoj nanostrukturirovannoj dobavkoj / E. A. Koleda [i dr.] // Vestnik Povolzhskogo gosudarstvennogo tekhnologicheskogo universiteta. Ser.: Materialy. Konstrukcii. Tekhnologii. - 2018. - № 2(6). - S. 24-34.

26. Zhdanok, S. A. Fiziko-mekhanicheskie harakteristiki betona, modificirovannogo plastificiruyushchej dobavkoj na osnove nanostrukturirovannogo ugleroda / S. A. ZHdanok [i dr.] // Inzhenerno-fizicheskij zhurnal. - 2019. - Tom 92, № 1 (yanvar'-fevral'). - C.14-20.

27. Zhdanok, S. A. Vliyanie plastificiruyushchej dobavki na osnove nanostrukturirovannogo ugleroda $v$ samouplotnyayushchejsya betonnoj smesi na ee tekhnologicheskie svojstva / S. A. ZHdanok [i dr.] // Inzhenerno-fizicheskij zhurnal. - 2019. - Tom 92, № 2 (mart-aprel'). C. 391-396.

28. Zhdanok, S. A. Physicomechanical Characteristics of Concrete Modified by a anostructured-Carbon-Based Plasticizing Admixture. S. A. Zhdanok [et al.] // Journal of Engineering Physics and Thermophysics. - 2019. - Vol. 92, №. 1. - pp. 14-20.
29. Zhdanok, S. A. Influence of the Nanostructured-Carbon-Based Plasticizing Admixture in a Self-Compacting Concrete Mix on Its Technological Properties/S. A. Zhdanok [et al.] // Journal of Engineering Physics and Thermophysics. - 2019. - Vol. 92, №. 2. - C. 376-382.

30. Zhdanok, S. A. Modifikaciya cementnyh betonov dobavkami, soderzhashchimi nanorazmernye materialy / S. A. ZHdanok [i dr.] // Inzhenerno-fizicheskij zhurnal. - 2020. - Tom 93, № 3 (maj-iyun'). C. 669-673.

31. Zhdanok, S. A. Modification of Cement Concrete by Admixtures Containing Nanosized Materials / S. A. Zhdanok, V. V. Potapov, E. N. Polonina, S. N. Leonovich //Journal of Engineering Physics and Thermophysics. - 2020. - Vol. 93, №. 3. - pp. 669-673.

32. Zhdanok, S. A. Prochnost' nanofibrobetona na rastyazhenie / S. A. Zhdanok [i dr.] // Inzhenerno-fizicheskij zhurnal. - 2020. - Tom 93, № 4 (iyul'-avgust). - C.1051-1055.

33. Zhdanok, S. A. Issledovanie metodom IK-spektroskopii stepeni aktivacii uglerodnyh nanomaterialov dlya modificirovaniya konstrukcionnogo betona / S. A. ZHdanok, E. N. Polonina, S. N. Leonovich // Stroitel'nye materialy. - 2020. - № 7. - S. 49-53.

34. Polonina, E. N. Mekhanizm povysheniya prochnosti cementnovodnyh obrazcov, modificirovannyh nanochasticami SiO2 i MUNT I E. N. Polonina [i dr.] // Inzhenerno-fizicheskij zhurnal. - 2021. - Tom 94, № 1 (yanvar'-fevral'). - C. 72-83.

35. Polonina, E. N. Mechanism for Improving the Strength of a Cement Material Modified by SiO2 Nanoparticles and Multiwall Carbon Nanotubes / E. N. Polonina, V. V. Potapov, S. A. Zhdanok S. N. Leonovich // Journal of Engineering Physics and Thermophysics. - 2021. - Vol. 94, № 1. - pp. 67-78.

Материал поступил в редакцию 06.05.2021 